https://doi.org/10.48009/2_iis_2007_39-44

\title{
FIRST AND LAST THINGS: UNDERSTANDING COMMUNICATION AND THE ORGANIZATIONAL INFOSCAPE
}

\author{
Rob Totterdale, Robert Morris University, robert.totterdale@accenture.com \\ Robert Joseph Skovira, Robert Morris University, skovira@rmu.edu
}

\begin{abstract}
This research study has focused primarily on meetings (on-ground and virtual) as a means of gaining insight into the interaction of corporate culture, communications, and information technology. The methodology is qualitative in nature. The investigative focus of this paper is the problem of the interaction of corporate culture, communications, and information technology, the information landscape, in a large global professional services firm. Power distance and uncertainty avoidance are two dimensions of the corporate infoscape.
\end{abstract}

Keywords: Infoscape, Information landscape, Communication, Information systems, Organizational culture, Power distance, Uncertainty avoidance.

\section{INTRODUCTION}

Communications between individuals and within organizations happen in many forms, often utilize an array of different technologies, can occur in a variety of settings, and can be orderly or chaotic. The culture of an organization significantly impacts how and when communications happen, and how individuals at all corporate levels participate. Further, organizational culture and structure typically influence how individuals interact with their peers, supervisors, and personnel outside the company. Hofstede and Hofstede [2005] consider this pattern of thinking, feeling and influence to be the "software of the mind" [p. 3].

\section{Organizational Context}

The corporate context of the research is a global professional services organization with over 3000 employees and $1000+$ professionals operating in 20+ locations in the United States and Europe which provides services to Fortune 500 companies. The organization is home to the systems and technology group (the research's focus) with over 100 employees. It is in a transitional state focusing on a major change initiative relating to the centralization of computing and telecommunications infrastructure. This is in addition to supporting on-going merger and acquisition activity, application development, and current operations. The systems and technology group itself is in a state of flux as new management positions have been filled and corporate roles redefined within the past twelve months.

The organization structure of the professional services company is consistent with Mintzberg's "Professional Bureaucracy" model [1, p. 76] which is characterized by few managerial levels, a strategic apex and a support staff. Further details of the model relating to direct supervision and standardization of work processes include the notion that "organizations formalize behavior to reduce its variability, ultimately to predict and control it” [5, p. 253].

The growth of the organization both organically and through acquisition has reinforced the need for effective communications and has introduced new aspects that need to be understood and assimilated. The frequency of communications (both meetings and email) within the systems and technology group requires a significant amount of time [4] on the part of the participants who routinely consume $75 \%+$ of their normal workday in communication-related activity. With substantial changes occurring in the business and a management focus on the need for "near real time responsiveness" to issues and concerns, an environment has been created that has enhanced global communications while at the same time has stretched the ability of individuals to effectively deal with the communications that they receive. There is a corporate expectation that individuals at the manager and above level (and in some cases lower levels) are reachable even after the end of the business work day. It is common for individuals to check their Blackberry's throughout the day and into the evening for messages. As one manager said "It is the last thing I do at night, and the first thing I do each morning."

\section{The Problem}

Because of the geographic dispersion of the systems and technology group, the senior management of the company and the professional user base, the ability to communicate accurately and on a timely basis has become critical for the company. The investigative focus of this paper is the problem of the interaction of corporate culture, communications, and information technology in a large global professional services firm. 


\section{Methodology}

Although there are many forms and methods of communications in use by the organization, this research study has focused primarily on meetings (on-ground and virtual) as a means of gaining insight into the interaction of corporate culture, communications, and information technology. The meetings observed had different purposes and attendees depending on the specific objectives for each session. Frequencies for meetings were semiweekly, weekly, monthly, quarterly and on an ad-hoc basis. Substantial overlap existed in personnel between the various meetings with the CIO being always included as either the organizer or as an attendee.

The primary location for many of the meetings was in the company's main office building which had eight large conference rooms set-up for client and internal meetings. A second office building that had two floors devoted to the company had another conference room that was used for overflow meetings for systems and technology personnel, internal groups and clients. Meetings were also held in the CIO's office when only two or three attendees were present.

In order to understand communications within the organization, the systems and technology department including the CIO, the directors who report to him, the managers who report to the directors, and selected individuals who report to the managers were observed in a number of communications environments (i.e. meetings). These meetings took place over a two month timeframe and included both local professionals and remote staff who participated via audio-conferencing. In addition, to gather more data on the culture and the communications processes, the CIO's direct supervisor (the $\mathrm{COO}$ ) and selected peers were included in the observations as participants in some of the meetings. Informants were used to complete the information gathering and analysis. One of the authors participated in a series of meetings that either included or were sponsored by the CIO of the organization.

Spradley's [7] methodology was followed for performing observations, for documenting a number of the domains, and for discovering themes discussed in the next sections. Field notes were written for each session and retained. Certain artifacts such as agendas and handout materials were also collected. Follow-up one-on-one sessions were conducted with informants (the CIO, individuals at the director level and manager level as well as with an outside consultant). A questionnaire was developed and distributed to a group of eight informants to gather additional information on the use of the Blackberry communications device.

\section{A CORPORATE INFOSCAPE}

As suggested by Grant, Hoehn and Skovira [3], "to study culture, communications and information technology in isolation, as discreet disciplines is to miss the absolute interconnectedness of these domains in actual lived situations” (p. 1).

An infoscape, an information landscape [6], is a metaphor that may be used to "see" information, information flows, and information use within the mix of an organizational culture (and its subcultures.) Culture consists of shared systems of meanings [2; 8; 9], shared practices [5], shared vocabulary and modes of communication [4], and commonly used things and tools, communal artifacts. Culture is the habits of feeling, thinking, speaking, and doing.

An infoscape also may be used to "see" that there is a human confection of frames of reference in the mix of organizational culture. Besides the organizational frame, the corporate culture, two other frames, communication and information technology, are of interest in this paper. To thickly describe [2] these frames is to pose questions and generate descriptive observational statements concerning what, why, how, and whom the frames reference. A thick description of the organizational culture, the organizational frame, also opens a discussion of the relation of power distance and uncertainty avoidance [5] to the attributes or dimensions of organizational culture, the organizational frame [5].

The professional services organization has a strong culture which Spradley [7] defines as "the acquired knowledge people to use to interpret experience and generate behavior" (p. 6). This acquired knowledge, culture, creates shared codes of communication and acts as an underlying shared system of meanings used to interpret behavior and situations [2; 8; 9].

Hofstede and Hofstede [5] define organizational culture “...[as] 'the collective programming of the mind that distinguishes the members of one organization from another"” (pp. 282-283). Organizational culture is an organization's practices, the "shared perception of daily practice" [5, p. 286]. Perception is a result of a habitual way of attending to things.

Hofstede and Hofstede's categories of organizational culture, the organizational frame, help structure individuals' perception of practices and habitual ways of doing things. There are 6 dimensions or sets of categories; organizations are "process oriented" or "results oriented" (p. 293), "employee oriented" or 
“job oriented” (pp. 293, 204), “parochial” or “professional” (p. 294), “open system” or "closed system” (p. 295), "loose control” or "tight control” (p. 295), and "pragmatic” or “normative” (p. 296).

Process oriented cultures are about doing things to complete the job; they focus on tasks designed to specific ends. Results oriented cultures are goaldrive, and concerned about the end product. Employee oriented organizations are concerned about personnel well being; decision making may be by committees or task forces. Job oriented organizations are about finishing the work or assigned tasks, keeping one's nose to the grindstone. Parochial cultures go home with the employee who considers themselves representatives. Professional cultures are about a person's knowledge to do the work or fill the role. Open (system) organizational cultures are quick assimilators of new hires; lines of communication and access are always available, both formal and informal. Closed (system) organizational cultures present a long learning curve and are not quick integrators of new people; communication is a formal state of affairs. Loose control organizations are about getting a job done without much reference to economic costs and concern about time used. Tight control organizations are focused on the economic costs and time used related to a project. Pragmatic organizations are about developing and delivering products or services to their customers. Normative organizations are about following policies and procedures in interacting with customers [5].

Power distance and uncertainty avoidance reflect the mindsets, the mental models, or habits of interacting within situations.

Power distance is a reflection of people's expectations of personal and on-the-job relationships, which are about sharing information and responsibility about events and activities. It is a cognitive-emotional characteristic of interaction, defining habitual modes of being dependent or independent within given situations. Power distance is about a system of meanings contextualizing perceived equality or inequality of relations among people [5]. As Hofstede and Hofstede [5] write "Power distance ....[is] the extent to which the less powerful members of institutions and organizations within a country expect and accept that power is distributed unequally “ (p. 46).

Uncertainty avoidance is about the tolerance of ambiguity and uncertainty in situations and with people. Ways of dealing with ambiguity are laws, technology, and religion [5]. Ways of communicating using technology, i.e., Blackberries and email, the constant being-available mode of communication may be representative of avoiding uncertain situations and may be a sign of an intolerance of ambiguity in states of affairs. The unknown element of business situations, a fear or uncertainty of something unmanageable happening, drives the excessive dependence upon communicative technologies, not merely as a means of "being-intouch,” but as a means of controlling and managing the unknown and ambiguous aspects of everyday business situations. This communicative defense against ambiguity and uncertainty shows up in the stresses of work and in a need for rules, both personal and institutional. The need for rules comes out in the need for order [5]. As Hofstede and Hofstede [5] write "Uncertainty avoidance ...[is] the extent to which the members of a culture feel threatened by ambiguous or unknown situations“ (p. 167).

\section{Organizational Frame}

With respect to power distance, examples noted include differences in business attire (formal and informal based on level), differences in ones ability to acquire the latest technology (e.g. the new Blackberry model), the ability to make decisions, control meetings [5] and control meeting content and the ability to access or communicate with other levels in the organization all based on one's status in the company. In addition to these power distance characteristics, it was observed that organizational roles above the $\mathrm{CIO}$ such as the COO, CEO and certain other professionals also can limit the authority of the CIO to make decisions, can impact the ability of his organization to reserve and commit resources, and can change his role to that of contributor or participant versus directing a meeting for higher level gatherings. Also, communications to professionals in the company originating from the systems and technology department often must be reviewed in advance prior to distribution reflecting both a high degree of control and a large power distance between organizational levels. Another area of differentiation which is common and consistent with concept of high power distance is the variation in compensation and benefits plans between the organization levels both within the department and between executive levels.

Uncertainty avoidance in the company reflects an environment where there is a high degree of risk avoidance at many levels of the organization. Executives in the organization are expected to be accessible virtually at all times and be able to respond to emails or voicemails even after normal working hours. In addition, key executives are also to be familiar with the work done in their areas so that if questions arise, they are in a position to respond. As a result, significant amounts of communications take 
place within the organization to insure that sufficient knowledge and understanding is available at the right levels. Additional examples include having subordinates attend meetings to insure that all questions can be answered and signing up for numerous email distribution lists to get updates on current status.

Another organizational and cultural aspect observed related to control. Structures and procedures were in place for scheduling and conducting meetings, for reporting of status and results, and for insuring that all employees were equipped with the proper technology. Some constraints relating to how and when certain communications were to take place were also indicative of a culture that had a level of control in place. This control aspect of the culture was indicative of a "closed system" and restrictive [5, p. 295] even if on the surface this was not how things appeared.

\section{Communications Frame}

Communications occur within the systems and technology department, between the department and senior levels of management and with other outside companies. Types of communications included desktop email, Blackberry email and phone, meetings with audio-conferencing, videoconferencing, cell phone, interactive messaging and correspondence. Two of the most significant forms of communications involve email and meetings. With respect to meetings, the organization has standard processes for how meetings are scheduled (rooms and people) and how resources such as equipment and communications lines are reserved (high structure).

Two cultural aspects of meetings relates to the reservation process. The first is that anyone including an outside vendor can request a meeting although only certain individuals have access to commit meeting resources internally. The second aspect deals with meeting duration. There is a cultural practice that allows for approximately a 10 minute overage on a schedule before the preceding meeting attendees are asked to leave the room (this typically results in bookings that are longer than the required meeting timeframe to provide a buffer). Additional characteristics of meetings include who initiates the meeting requests, where meetings are held and the type of communications equipment that is available for a meeting.

The structure and processes in place relating to the planning and execution of meetings are indicative of a large power index that places a premium on a person's level in the organizational hierarchy and a high degree of uncertainty avoidance that encourages communications and sharing of information on a regular basis to minimize ambiguity and to improve information available for decision making.

Another dimension of communications that relates to power distance and uncertainty avoidance as well as the cultural climate of professionalism [5, p. 294], involves the ability of professionals in the company as well as senior management to directly access individuals in the systems and technology group with issues thus bypassing certain helpdesk processes or organizational hierarchies that exist. This cultural practice, an indicator of a pragmatic orientation [5, p. 296], presents a number of issues and concerns regarding how to deal with problems effectively and how to avoid creating unnecessary and confusing communication streams between different parts of the organization. In addition, senior executives seeking to gain quick resolution of a problem, may send inquiries to multiple individuals for support at multiple levels in the systems and technology organization structure which occasionally results in duplicative work efforts, excessive communications streams, and confusion on the part of the end user and the systems and technology group. When these information flows occur, the CIO believes that in short order "another line item will be added to the can't do anything right list."

The normal flow of information and contours of the infoscape [6], however, follow the primary organization structure and tends to be hierarchical in nature with information flowing from top to bottom and from bottom to top. Interactions with professional and non-professional users with the systems and technology organization are made directly with the support group to deal with specific operating issues. It is when issues become significant (or are viewed as significant by the user) that the normal support communications flows are disrupted and alternative information flows occur. The management level usually has the same information uses as the systems and technology group although at a higher level and in some cases different areas (e.g. mergers and acquisitions).

\section{Codes in use}

Another aspect of communications which is based in large part on culture relates to the usage of codes or symbols [2; 4]. These codes or symbols are defined by Hofstede and Hofstede [5] as "words, symbols, gestures, pictures, or objects that carry a particular meaning which is only recognized by those who share the culture" (p. 7). Although each level in the organization was observed to have a vocabulary of codes that were used with some regularity, the systems and technology group utilized codes 
extensively particularly with meetings that had managers and more junior personnel as attendees. The meetings such as the "Major Change Initiative" were high in context [4] such that it was necessary to understand the vocabulary in order to understand the messages that were delivered. At times, because of the extensive use of codes, a person discussing a topic would have to explain the terminology to other members in the meeting.

Local codes, apart from those typically found in a technology setting, were used to name individuals in the meeting such as "cheetah" which was the name given to the manager who ran the Major Change Initiative Meeting and the "gazelles" who were identified as two of the managers who handled detail tasks. It was suggested by an informant that the "gazelles" were subject to "having their butts kicked" by the cheetah if they did not perform as expected. The "cheetah" also argued that since a vendor had not delivered on their technology and thus required the "organization to be on the bleeding edge...licking the razor blade", that the vendor should be required to pay for incremental costs incurred. Types of codes observed included those dealing with telecommunications (e.g. IP, LAN, WAN, PBX), infrastructure (e.g. SAN, EMC, DMZ, VM), applications (e.g. SP2, Compuware, PST), end users and industry specific terminology.

\section{Blackberry}

During the course of conducting the observations, the pervasive use of Blackberry devices (a handheld wireless device which supports email and voice communications) was noted and additional information gathering and observation was performed to understand how this technology is used by the organization and how it affects communications.

A key element of the company culture, the Blackberry devices, serves as an extension of their computing and communications infrastructure. Culturally, Blackberries indicate a communicative leash that allows for uncertainty avoidance by restrictive control of professional time [5, p. 295]. Average daily email volume received by individuals in the systems and technology management group range from 75 to over 400. Access to emails and voicemails which are integrated with the email system is through either an individual's desktop computer or through their Blackberry. Blackberry devices and desktop units are typically given to new employees within the first few days of employment. All systems and technology management, all executives of the company and all of the professionals (over 1000 users) have the Blackberries and are expected to be accessible throughout the day and into the evening in emergency situations in effect being "always on call." For other than certain corporate meetings which are declared "No Blackberry Zones", it is common for all attendees to carry their Blackberries and routinely check for messages and respond to messages during the course of a meeting. Because of the integration of voice messages with the email system, very few managers use the devices for voice communications. Also, since the company does not reimburse individuals for personal use of the voice or cellular service, it is not frequently used although it is made available. Almost all of the Blackberry users believe that it is a good productivity tool but also acknowledge that it does impact their ability to focus and concentrate in meetings. As one informant indicated, "it allows me to work anywhere and at any time.”

One individual who is new to the culture and organization and who is at the management level (the Director of Technology), consciously does not take his Blackberry to meetings. His decision is based on his belief that it degrades the productivity of individuals and overall increases the amount of time needed to conduct meetings because of lack of attention. He does feel that there is value in having the devices but has established rules for himself that limit his usage throughout the day and evening. The Director also expressed concern that there is a perception that "you must not be working if your Blackberry is not on at night" and that "if you don't respond to a message in a short period of time you must not be paying attention.”

Given the large volume of emails that are received each day, further analysis was performed to assess the nature of the emails based on informant feedback. This analysis concluded that on average only $10 \%$ of the email messages were considered important requiring a response within a one hour timeframe while $90 \%$ were considered to be either informational (requiring no response) or of lower importance. Examples of informational messages include an announcement regarding the closing of an office for a day or that a particular server was out of service. Additional observations noted that during a typical one hour meeting, all participants would access their Blackberry's at least once and that $25-35 \%$ of the attendees would be either checking or responding to email on an on-going basis even while discussions were taking place. Usage of the Blackberry declined in a meeting when the $\mathrm{CIO}$ or a senior director was speaking.

\section{Information Technology Frame}

The final frame to be addressed is the technology frame. As demonstrated in the previous discussions, 
technology usage is pervasive in the organization and is reflected as an integral component of the organizational and communications frames that have been addressed in previous paragraphs. Examples of the technology frame components include the use of email, Blackberry devices, meeting scheduling software, voicemail, videoconferencing, networking and audio-conferencing. In addition, many of the "code" systems in place reflect those used by information technology professionals.

The technology infrastructure that has been deployed facilitates and speeds communications between individuals, groups of individuals and clients on a global basis. Other technologies implemented in the organization provide for capturing and storing the communications in electronic form to provide control and to enhance the effectiveness of communications.

\section{CONCLUSIONS}

This paper has examined three interrelated frames consisting of organization (culture), communications and information technology for the systems and technology group at a large global professional services firm. In many cases, it is the organization's cultural component that frames the manner in which communications take place, how frequently they occur, and who participates in the communications. It is also the cultural aspect that drives the type of technology that is used and the manner in which it is used at various levels in the organization. The extensive use of email and the Blackberry are examples of technology that has been implemented to encourage "near real time" availability of personnel and communications in order to minimize uncertainty and ambiguity.

It is however, the control dimension of the culture (e.g. management's perceived need for information and rapid responses to problem situations) combined with a "large power distance" that creates actions and behaviors that help to minimize uncertainty. Responses to minimize uncertainty can be observed in the various communications approaches that are in use (i.e. meetings, emails) that are supported by a host of technologies that facilitate the more rapid movement of information throughout the organization.

\section{REFERENCES}

1. Bolman, L. G., \& Deal, T. E. (2003). Reframing organizations: Artistry, choice and leadership $3^{\text {rd }}$ Ed. San Francisco: Jossey-Bass.

2. Geertz, C. (1973). The interpretation of cultures. New York: Basic Books.

3. Grant, A., Hoehn, C. A., \& Skovira, R. J. (2006). Fabricating convergence: Reflections on crossing imagined boundaries. Prepublication.

4. Hall, E. T. (1981). Beyond culture. New York: Anchor Books Random House.

5. Hofstede, G., \& Hofstede, G. J. (2005). Cultures and organizations. New York: McGraw-Hill.

6. Skovira, R. J. (2004). Using informational landscape as a model to understand information use and design within organizations. Issues in information Systems, V(1): 308-314.

7. Spradley, J. P. (1980). Participant observation. New York: Wadsworth Thomson Learning.

8. Trompenaars, F. (1994). Riding the waves of culture: Understanding diversity in global business. London: The Economist Books.

9. Trompenaars, F. \& Woolliams, P. (2003). Business across cultures. Chichester, England: Capstone Publishing. 